\title{
Assessment of muscular strength with the modified sphygmomanometer test: what is the best method and source of outcome values?
}

\author{
Lucas A. C. Souza1 ${ }^{1}$, Júlia C. Martins ${ }^{1}$, Juliana B. Moura², \\ Luci F. Teixeira-Salmela ${ }^{1,2}$, Fátima V. R. De Paula ${ }^{1,2}$, \\ Christina D. C. M. Faria ${ }^{1,2}$
}

\begin{abstract}
Background: Tests that are usually employed for the clinical assessment of muscular strength have notable disadvantages. The Modified Sphygmomanometer Test (MST) is a promising method because it is low-cost and provides objective measures. Objectives: To investigate the most adequate method and sources of outcome values for the assessment of strength with the MST. Method: Methodological study with 40 healthy adults $(22.98 \pm 2.26$ years), who did not practice physical activity regularly. The strength of the flexors and extensors of the elbow and knee, the handgrip of the dominant side and anterior trunk flexors were randomly assessed with portable dynamometers and the MST (bag and cuff adaptations, and sphygmomanometer without adaptation) by a single examiner. An independent examiner read and recorded the values. The sources of the investigated outcome values were the first trial and the means of two and three trials. One-way ANOVAs and Pearson Correlation Coefficients were used for the analyses $(\alpha=0.05)$. Results: For the MST methods applied to assess all muscular groups, similar values were found for all sources of outcome values $(0.01<F \leq 0.26 ; 0.77 \leq p \leq 1.00)$ with significant and positive correlations between the measures obtained with the dynamometers $(0.51 \leq r \leq 0.94 ; p \leq 0.003)$. Conclusions: All MST methods showed adequate results for the assessment of strength in healthy individuals, and after familiarization, only one trial was sufficient to provide reliable measures. The sphygmomanometer without adaptation is not time consuming, compared to the other adaptations, and showed the capability of measuring higher values of strength. The bag method was easily trained to be used and stabilized.
\end{abstract}

Keywords: rehabilitation; muscular strength; assessment; upper extremity; lower extremity; trunk.

\section{HOW TO CITE THIS ARTICLE}

Souza LAC, Martins JC, Moura JB, Teixeira-Salmela LF, De Paula FVR, Faria CDCM. Assessment of muscular strength with the modified sphygmomanometer test: what is the best method and source of outcome values?. Braz J Phys Ther. 2014 Mar-Apr; 18(2):191-200. http://dx.doi.org/10.1590/S1413-35552012005000149

\section{Introduction}

Given the need for an objective assessment of muscular strength within clinical settings and the limitations of commonly used methods to measure this outcome, such as the manual muscle testing (MMT) and the portable dynamometry, the Modified Sphygmomanometer Test (MST) is an interesting alternative. Although the MMT is widely used within clinical contexts, it is a descriptive, subjective and less sensitive method ${ }^{1}$. The portable dynamometer is capable of providing accurate, valid, reliable, and sensitive measurements of strength ${ }^{2-4}$; however, its relatively high cost has hindered its use in most clinical contexts, including those in which there are insufficient financial resources. The MST provides objective, reliable, and valid measurements of strength $^{5-7}$, and it has a low cost relative to the dynamometer.

The MST involves an aneroid sphygmomanometer, a device that is portable, easily obtained, and commonly acquired by healthcare professionals for the measurement of blood pressure. This is a quick and easy test, which follows procedures similar to those used with the MMT and portable dynamometers ${ }^{6}$. However, some type of adaptation to the conventional sphygmomanometer is usually required ${ }^{8}$.

A systematic review showed that the MST has been used with the sphygmomanometer adapted in the bag and cuff methods ${ }^{8}$. The validity and

\footnotetext{
${ }^{1}$ Rehabilitation Sciences Graduate Program, Universidade Federal de Minas Gerais (UFMG), Belo Horizonte, MG, Brazil ${ }^{2}$ Physical Therapy Department, Universidade Federal de Minas Gerais (UFMG), Belo Horizonte (MG), Brazil Received: 07/01/2013 Revised: 09/20/2013 Accepted: 10/23/2013
} 
reliability of the measurements obtained with these adaptations have been investigated for the upper limb (UL) muscles in healthy adults ${ }^{7,9}$, the elderly ${ }^{6}$, and individuals with rheumatoid arthritis ${ }^{10}$ as well as in the lower limb (LL) and trunk muscles in individuals with rheumatoid arthritis ${ }^{5}$ and low back pain $^{11}$. The results were significant and of moderate to high magnitude ${ }^{12}$. However, it is unknown whether this method is better than the others. In addition, the use of the MST without adaptation of the sphygmomanometer could expand its use, but has not yet been investigated.

Most studies using the $\mathrm{MST}^{8}$ used the mean of three trials to obtain a final result. However, no study has investigated the best way to operationalize the test, that is, to determine how many repetitions are required to obtain reliable measurements. Should lower number of repetitions be sufficient, the feasibility of using the MST within clinical settings will be greater ${ }^{13}$.

The MST has the potential to be used within clinical contexts because it uses portable and lowcost equipment that is easily accessible to healthcare professionals and provides objective measurements of strength. Therefore, the establishment of the best method for its use is required. Thus, the present study aimed to investigate the best method (bag, cuff, and non-adapted sphygmomanometer) and the most appropriate sources of outcome values (first trial and means of two and three trials) for the assessment of strength with the MST.

\section{Method}

\section{Participants}

Healthy young adults of both genders were recruited from the general community, according to the following criteria: Had ages between 20 to 30 years, physical activity levels rated as insufficient or inactive ${ }^{14}$, and were able to perform the proposed tests. Health conditions that could affect the measurement of strength and the presence of pain during the evaluations were used as exclusion criteria. All participants provided consent, based upon previous approval from the University Ethical Research Committee of the Universidade Federal de Minas Gerais (UFMG), Belo Horizonte, MG, Brazil (\# 04 92.0.203.000-10).

\section{Procedures}

After verification of eligibility, demographic and physical data were collected from all participants. Their dominant UL was determined as the limb most frequently used to write ${ }^{15}$, while the dominant LL as the one they would more easily kick a ball ${ }^{16}$. In total, 40 subjects were included, whose demographic and physical characteristics are given in Table 1 .

The strength of the elbow and knee flexor and extensor muscles on the dominant side was evaluated with a Microfet ${ }^{\circledR}$ digital manual dynamometer (Hoggan Health Industries, UT, USA), and grip strength with the SAEHAN ${ }^{\circledR}$ hydraulic hand dynamometer (SAEHAN Corporation, Korea, Model SH5001). A DuraShock ${ }^{\mathrm{TM}}$ Tycos $^{\circledR}$ aneroid sphygmomanometer (Welch Allyn Inc., NY, USA, Model DS-44) was used for the evaluation of all muscular groups by three methods (bag and cuff adaptations and non-adapted sphygmomanometer).

For the bag method adaptation, the inflatable part of the outer velcro constituting the cuff of the equipment was removed, and this structure was folded into three equal parts and placed in a cotton bag with a zipper ${ }^{5}$. After being adaptated, the modified sphygmomanometer was $3.5 \mathrm{~cm}$ long, 10 $\mathrm{cm}$ wide, and $7 \mathrm{~cm}$ thick (Figure 1A). For the cuff method adaptation, the inflatable part, inserted into the velcro cuff, was folded into four equal parts, and the remainder of the cuff was wrapped around the inflatable part ${ }^{5}$ and fixed with adhesive tape. Once adapted, the modified sphygmomanometer had the following dimensions: $14 \mathrm{~cm}$ long, $6 \mathrm{~cm}$ wide, and $4.5 \mathrm{~cm}$ thick (Figure 1B). The dimensions of the non-adapted sphygmomanometer were $27 \mathrm{~cm}$ long, $14 \mathrm{~cm}$ wide, and $9 \mathrm{~cm}$ thick (Figure 1C).

All employed equipments (portable dynamometers and sphygmomanometer) were acquired for the present study and arrived factory-calibrated, according to the manufacturers' instructions. Before the strength assessments, the principal investigator randomized the equipment order, by drawing. After the adaptation of the sphygmomanometer and before its use for data collection, calibration procedures were performed with $5 \mathrm{~kg}$ weights to verify whether the equipment provided consistent measurements throughout the study, for possible adjustments of systematic errors, if necessary. Due to the methodological nature of the study, the identification of systematic errors is crucial ${ }^{17}$, and possible sources 
Table 1. Subjects' demographic and physical characteristics $(n=40)$.

\section{Variables}

Results

Age (years): mean $\pm \mathrm{SD}$; range [min-max]

Body mass index $\left(\mathrm{kg} / \mathrm{m}^{2}\right)$ : mean $\pm \mathrm{SD}$

$21.52 \pm 3.00$

Gender

Men: number (\%)

$18(45 \%)$

Women: number $(\%)$

$22(55 \%)$

Dominant Upper Limb

Right: number (\%)

Left: number (\%)

$7(17.5 \%)$

Dominant Lower Limb

Right: number (\%)

$36(90 \%)$

Left: number (\%)

$4(10 \%)$

SD: Standard Deviation.

of systematic error could be the loss of calibration of the sphygmomanometer, which was used for all the MST measurements. This calibration procedure was performed according to previous recommendations ${ }^{6}$, as follows: The sphygmomanometer was inflated to $100 \mathrm{~mm} \mathrm{Hg}$ and its valve was kept closed to remove the folds from the inflatable portion. Then, the pressure was reduced to $20 \mathrm{~mm} \mathrm{Hg}$, and the valve was closed again to prevent leakage ${ }^{6}$, providing a measurement range between 20-304 mm Hg. To stack the weight plates on the equipment, a wood apparatus was built to keep them aligned (Figure 2). All weights were numbered and consistently stacked on top of each other in the same sequence. The correlation between the weights (plates) and the values in $\mathrm{mm}$ Hg was high $(0.97 \leq r \leq 1.00 ; p \leq 0.001)$, with a $2-13 \%$ coefficient of variation. No systematic errors were observed.

After calibration, the first examiner (examiner 1) performed the strength assessments and the second examiner (examiner 2) independently read and recorded all the measurement values. The use of two independent observers is recommended to ensure the internal validity of methodological studies, and for this reason, this procedure was adopted ${ }^{17}$. Both examiners were previously trained in their respective functions: examiner 1 to perform all procedures established for the strength measurements (detailed later), and examiner 2 to correctly read and record the strength values obtained with the dynamometers and sphygmomanometer. The manometer of the sphygmomanometer was analogic with measurement scale intervals of $2 \mathrm{mmHg}$.

The strength assessments followed the order of the equipment determined by randomization. The entire procedure for data collection, including the positioning of the participant, the body segment, and the used equipment, as well as the verbal feedback provided during the tests, was standardized, following recommendations in the literature ${ }^{18-23}$ and detailed below. For all equipment/assessment methods, the same procedures were adopted to ensure the internal validity of the study ${ }^{17}$. Thus, the only carried out change was related to the device/method: portable dynamometers or sphygmomanometer with three different methods (bag and cuff adaptations and without adaptation).

The following positions were adopted: for the evaluation of elbow flexors and extensors, the subjects remained in supine position with their forearms in the neutral position and elbows flexed at $90^{\circ 18}$; for the knee flexors and extensors, they were seated on a table, with their legs hanging naturally over the edge of the table at approximately 90 degrees and hands on the thighs ${ }^{20}$; the handgrip measurements were obtained with the subject seated on a chair without armrests, feet supported, shoulders adducted, forearms in the neutral position and elbows flexed $90^{\circ 19}$; the assessment of the anterior trunk flexors was conducted with individuals sitting on a chair without armrests, feet supported, knees bent at $90^{\circ}$ and hands relaxed and resting on the thighs ${ }^{23}$. The participants were instructed not to perform compensatory movements during the strength tests.

The equipment placement was as follows: elbow flexors, distal and anterior to the forearm ${ }^{24}$; elbow extensors, distal and posterior to the forearm ${ }^{24}$; trunk flexors, on the sternum below the jugular notch ${ }^{23}$; knee flexors, distal and posterior to the $\mathrm{leg}^{24}$, and knee extensors, distal and anterior to the $\mathrm{leg}^{24}$. The sphygmomanometer was positioned parallel to the segment in a way to resist the movement of the tested muscle group.

Immediately prior to the strength assessments, a demonstration and familiarization with the equipment and procedures were performed. During testing, the subjects were instructed to perform a maximal isometric contraction for $5 \mathrm{~s}$, and the peak force value was recorded. The volunteers received verbal encouragement to initiate the movement and to hold the contraction: "one, two, three, and now! Force!... 

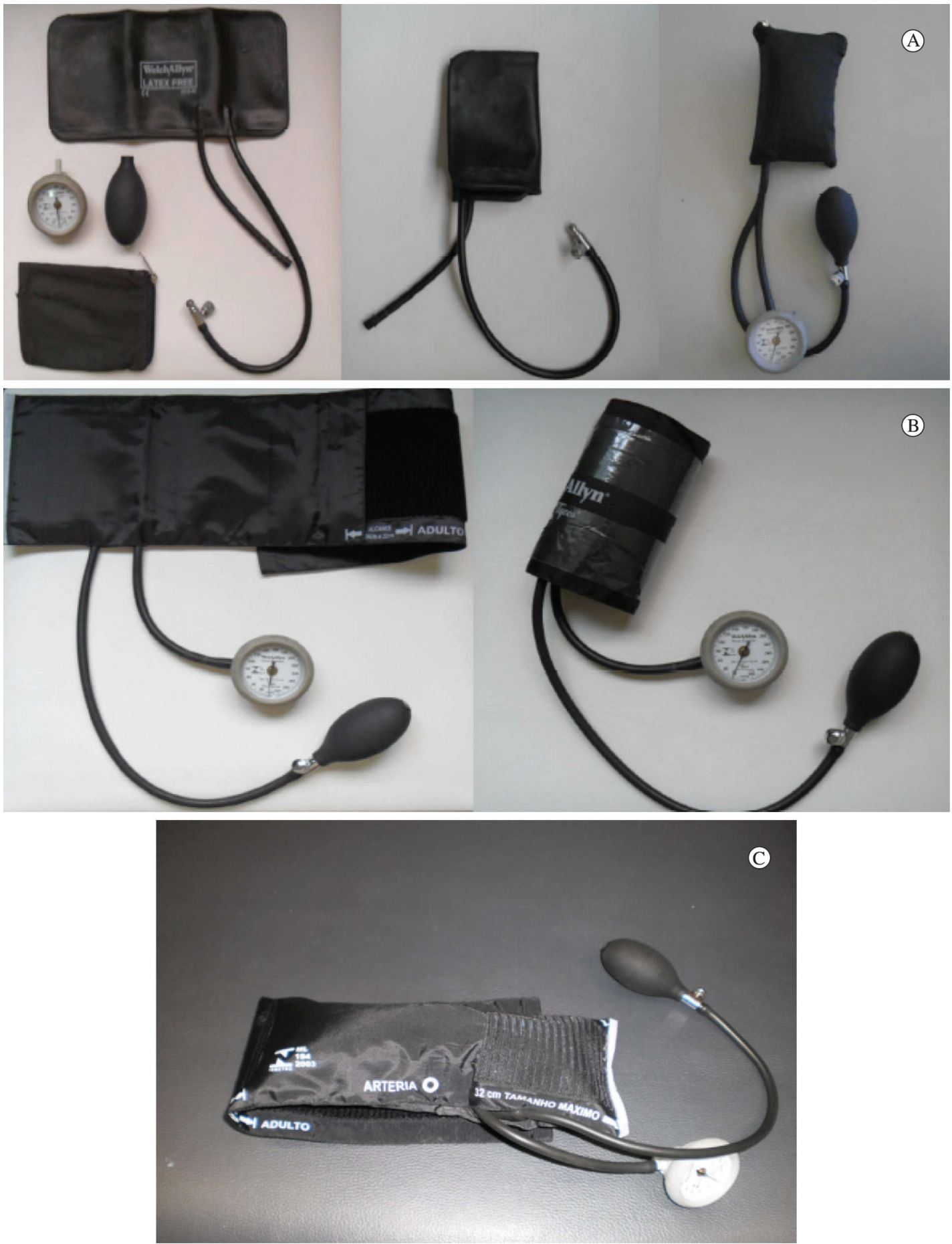

Figure 1. Sphygmomanometer adaptation methods for the assessment of muscular strength: (A) bag method; (B) cuff method; (C) without adaptation.

force!... force!... relax!"21. Three trials were obtained for each assessed muscle group, and a 15 s restinterval was provided between the repetitions ${ }^{22}$. The muscle groups were always evaluated in the same order: the elbow and knee flexors and extensors and then, the anterior trunk flexors and handgrip. Before each measurement, the examiner ensured the preinflation of the equipment to $20 \mathrm{mmHg}$. 


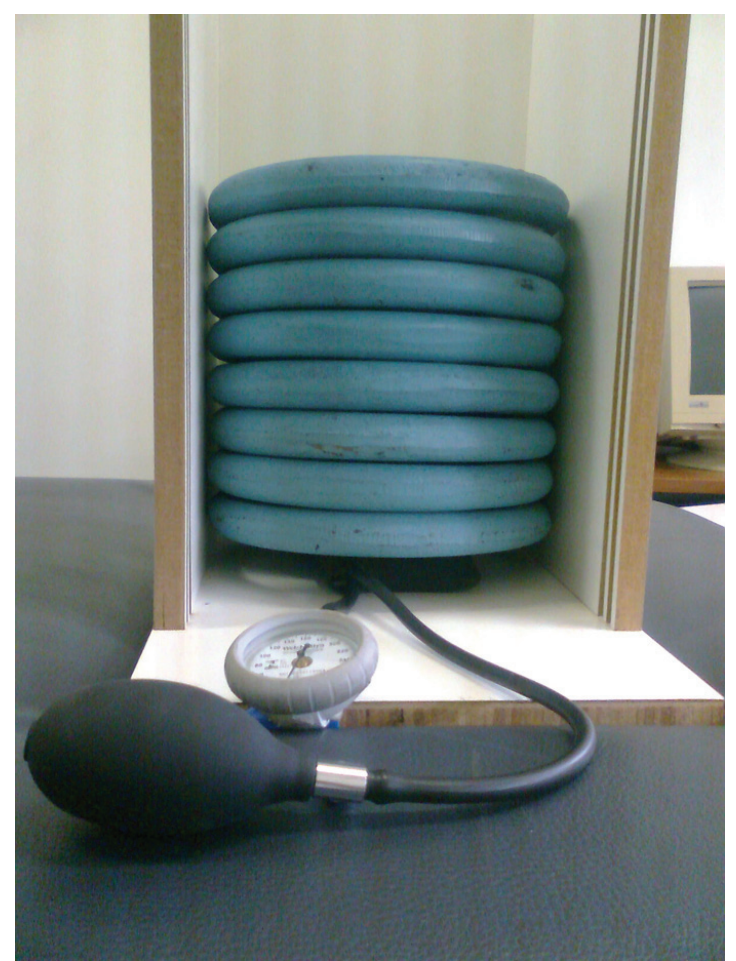

Figure 2. Apparatus for the calibration of the sphygmomanometer using $5 \mathrm{~kg}$ weights.

\section{Statistical analysis}

Descriptive analysis and normality tests were performed for the categorical variables and the main outcome measurements of strength. To compare the strength values obtained for each muscular group and the different sources of outcomes (first trial and the means of two and three trials) for a particular MST method (bag, cuff, or without adaptation), one-way analysis of variance (ANOVA) was employed. To determine the correlations between the measurements obtained with the portable dynamometer and the MST methods, considering the various sources of outcomes and muscular groups, Pearson's correlation coefficients were calculated. When the coefficients reached significance, the magnitudes of the correlations were classified as follows ${ }^{12}$ : very low $\leq 0.25$; low: from $0.26-0.49$; moderate: 0.50 0.69; high: 0.70-0.89; and very high: 0.90-1.00. All analyses were performed using SPSS for Windows (SPSS Inc., Chicago, IL, USA), with a significance level of $5 \%$.

\section{Results}

Table 2 gives the descriptive data of the strength measurements for all MST methods, as well as the ANOVA results regarding the comparisons between the various sources of outcomes. The values provided by the different sources of outcomes were similar for all evaluated methods $(0.01<F \leq 0.26$; $0.77 \leq p \leq 1.00)$. Furthermore, the sample size varied according to the assessed muscular group and the MST method. As shown by the $n$ value, the nonadapted sphygmomanometer was able to provide measurements of all assessed muscular groups. For the bag adaptation, 27 strength measurements were lost, whereas for the he cuff adaptation, 19 measures were lost, with the greatest losses arising from the evaluations of the knee extensors and handgrip muscles. These losses were due to equipment limitations in reading the strength values of very strong individuals and to the difficulty of the evaluator in stabilizing the body segment during the measurement of the knee extensor muscles of one of the participants.

For all muscular groups and sources of outcomes, significant and positive correlations were observed between the measurements obtained with the portable dynamometers and the three MST methods (Table 3). The magnitudes of the correlations were classified as moderate to very high $(0.51 \leq r \leq 0.94 ; p \leq 0.003)$. In general, the nonadapted sphygmomanometer and the bag adaptation showed correlations that were similarly classified and of greater magnitude, compared with those of the cuff adaptation to most muscular groups.

\section{Discussion}

To our knowledge, the present study was the first to investigate the best MST method for the assessment of muscular strength in healthy individuals. In addition, it aimed to determine whether the sphygmomanometer without any type of adaptation was an appropriate method for assessing strength and to identify the best source of outcome values when using the MST. All MST methods demonstrated significant and suitable correlations with the portable dynamometer for all sources of outcomes. However, some distinct characteristics between the methods should be considered. 
Table 2. Descriptive statistics (means \pm SD) of the measures of muscular strength with the three Modified Sphygmomanometer Test (MST, mm Hg) methods and the ANOVA results regarding the comparisons between the various sources of outcome scores for all employed methods.

\begin{tabular}{|c|c|c|c|c|c|c|}
\hline $\begin{array}{l}\text { Muscular } \\
\text { group }\end{array}$ & MST method & $n$ & First trial & $\begin{array}{c}\text { Mean of two } \\
\text { trials }\end{array}$ & $\begin{array}{c}\text { Mean of three } \\
\text { trials }\end{array}$ & $\operatorname{ANOVA}(F ; p)$ \\
\hline \multirow{3}{*}{ Elbow flexors } & Bag method & 39 & $213.49 \pm 44.61$ & $215.28 \pm 44.50$ & $215.08 \pm 42.95$ & $0.02 ; 0.98$ \\
\hline & Cuff method & 39 & $198.46 \pm 43.48$ & $201.18 \pm 40.19$ & $202.53 \pm 38.82$ & $0.10 ; 0.91$ \\
\hline & Without adaptation & 40 & $132.35 \pm 38.04$ & $132.58 \pm 37.59$ & $132.02 \pm 36.55$ & $0.00 ; 1.00$ \\
\hline \multirow{3}{*}{ Elbow extensors } & Bag method & 40 & $158.15 \pm 40.48$ & $157.30 \pm 41.32$ & $156.63 \pm 41.01$ & $0.01 ; 0.99$ \\
\hline & Cuff method & 39 & $158.00 \pm 37.19$ & $157.26 \pm 34.11$ & $157.11 \pm 33.24$ & $0.01 ; 0.99$ \\
\hline & Without adaptation & 40 & $102.85 \pm 30.91$ & $101.23 \pm 28.60$ & $100.62 \pm 27.78$ & $0.06 ; 0.94$ \\
\hline \multirow{3}{*}{ Knee flexors } & Bag method & 39 & $195.38 \pm 42.82$ & $196.09 \pm 43.29$ & $196.03 \pm 43.36$ & $0.00 ; 1.00$ \\
\hline & Cuff method & 39 & $198.15 \pm 49.86$ & $198.56 \pm 49.17$ & $199.78 \pm 49.45$ & $0.01 ; 0.99$ \\
\hline & Without adaptation & 40 & $124.25 \pm 27.59$ & $123.70 \pm 25.86$ & $123.68 \pm 25.50$ & $0.01 ; 0.99$ \\
\hline \multirow{3}{*}{ Knee extensors } & Bag method & 31 & $237.61 \pm 43.08$ & $239.74 \pm 40.47$ & $237.56 \pm 41.46$ & $0.03 ; 0.97$ \\
\hline & Cuff method & 32 & $237.25 \pm 44.05$ & $237.84 \pm 43.55$ & $239.08 \pm 42.21$ & $0.02 ; 0.99$ \\
\hline & Without adaptation & 39 & $154.31 \pm 32.24$ & $154.13 \pm 30.27$ & $153.83 \pm 29.81$ & $0.00 ; 1.00$ \\
\hline \multirow{3}{*}{ Trunk flexors } & Bag method & 40 & $187.30 \pm 49.90$ & $186.53 \pm 49.30$ & $187.40 \pm 50.07$ & $0.00 ; 1.00$ \\
\hline & Cuff method & 36 & $200.67 \pm 51.24$ & $201.06 \pm 48.73$ & $202.30 \pm 48.41$ & $0.01 ; 0.99$ \\
\hline & Without adaptation & 40 & $110.20 \pm 30.93$ & $111.95 \pm 30.95$ & $113.03 \pm 31.59$ & $0.08 ; 0.92$ \\
\hline \multirow{3}{*}{ Handgrip } & Bag method & 24 & $237.75 \pm 44.80$ & $233.42 \pm 44.03$ & $230.86 \pm 42.66$ & $0.15 ; 0.86$ \\
\hline & Cuff method & 35 & $226.06 \pm 55.18$ & $219.54 \pm 52.30$ & $217.37 \pm 50.86$ & $0.26 ; 0.77$ \\
\hline & Without adaptation & 40 & $148.95 \pm 45.93$ & $147.80 \pm 44.78$ & $146.52 \pm 43.67$ & $0.03 ; 0.97$ \\
\hline
\end{tabular}

SD: Standard deviation; ANOVA: Analyses of variance.

Among the studies that evaluated the associations between the measurements obtained with the MST and portable dynamometry, which is considered the gold standard for the assessment of isometric strength ${ }^{2}$, significant and high correlations $(0.75 \leq r \leq 0.98)$ were found only for the elbow flexors of healthy individuals using the cuff adaptation ${ }^{9}$, handgrip muscles of elderly individuals ${ }^{25}$, and healthy adults using the bag $^{7,26}$ and cuff ${ }^{27}$ adaptations, as well as the anterior trunk flexors of healthy individuals and individuals with low back pain using the bag adaptation ${ }^{11}$. Most previous studies have investigated the correlations between the MST and portable dynamometry measures of UL muscular groups, while no study has evaluated these associations for the LL muscles or made use of the non-adapted sphygmomanometer.

Two studies used the bag and cuff adaptations for the assessment of strength of individuals with rheumatoid arthritis and found no significant differences between the measurements provided by the two methods ${ }^{5,10}$. However, the authors showed differences between the two MST adaptations and reported that the bag adaptation is more elastic, requires more air in the pre-inflation of the equipment, has a larger contact area with the skin of the participant and reaches higher pressure values when an external force is applied ${ }^{5,10}$. In the present study, the measurements obtained with the bag adaptation showed higher values than those obtained with the cuff adaptation only for the elbow flexors and the handgrip muscles, with the other measurements showing similarities between the two methods or lower values with the bag adaptation (knee flexors and anterior trunk flexors). The measurements obtained with the non-adapted sphygmomanometer were lower than those registered with other methods for all assessed muscular groups, possibly due to its larger contact area, which may have provided lower pressure values, when subjected to external forces.

The MST investigation using the non-adapted sphygmomanometer aimed to raise the potential clinical use of the equipment, because it does not 
Table 3. Correlation coefficients between the measures obtained with the three Modified Sphygmomanometer Test (MST) methods and the portable dynamometer considering the various sources of outcome scores.

\begin{tabular}{|c|c|c|c|c|c|}
\hline \multirow[t]{2}{*}{ Muscular group } & MST method & $\mathbf{n}$ & First trial $(r)$ & Mean of two trials $(r)$ & Mean of three trials $(r)$ \\
\hline & Bag method & 39 & $0.86^{*}$ & $0.87 *$ & $0.87 *$ \\
\hline \multirow[t]{3}{*}{ Elbow flexors } & Cuff method & 39 & $0.77 *$ & $0.81 *$ & $0.83^{*}$ \\
\hline & Without adaptation & 40 & $0.86^{*}$ & $0.89 *$ & $0.91 *$ \\
\hline & Bag method & 40 & $0.89^{*}$ & $0.93 *$ & $0.94 *$ \\
\hline \multirow[t]{3}{*}{ Elbow extensors } & Cuff method & 39 & $0.70^{*}$ & $0.74 *$ & $0.74 *$ \\
\hline & Without adaptation & 40 & $0.89^{*}$ & $0.91 *$ & $0.92 *$ \\
\hline & Bag method & 39 & $0.84 *$ & $0.84 *$ & $0.87 *$ \\
\hline \multirow[t]{3}{*}{ Knee flexors } & Cuff method & 39 & $0.74^{*}$ & $0.80 *$ & $0.81 *$ \\
\hline & Without adaptation & 40 & $0.85^{*}$ & $0.87 *$ & $0.85^{*}$ \\
\hline & Bag method & 31 & $0.74 *$ & $0.75 *$ & $0.74 *$ \\
\hline \multirow[t]{3}{*}{ Knee extensors } & Cuff method & 32 & $0.51^{*}$ & $0.59 *$ & $0.57 *$ \\
\hline & Without adaptation & 39 & $0.66^{*}$ & $0.65 *$ & $0.64 *$ \\
\hline & Bag method & 40 & $0.90^{*}$ & $0.91 *$ & $0.91 *$ \\
\hline \multirow[t]{3}{*}{ Trunk flexors } & Cuff method & 36 & $0.81^{*}$ & $0.87 *$ & $0.88 *$ \\
\hline & Without adaptation & 40 & $0.89 *$ & $0.91 *$ & $0.91 *$ \\
\hline & Bag method & 24 & $0.56^{*}$ & $0.64 *$ & $0.76 *$ \\
\hline \multirow[t]{2}{*}{ Handgrip } & Cuff method & 35 & $0.79 *$ & $0.83 *$ & $0.73 *$ \\
\hline & Without adaptation & 40 & $0.72 *$ & $0.75 *$ & $0.73 *$ \\
\hline
\end{tabular}

$* p \leq 0.003 ; r$ : Pearson correlation coefficient.

require any extra cost or any time demand from the professional to perform certain adaptations. Moreover, this was the only method capable of providing measures of strength for all assessed muscular groups and individuals, with the exception of the knee extensors of a male participant, whose strength could not be evaluated by examiner 1 , even with the dynamometer, due to the difficulty of manual stabilization of the segment. This problem most likely occurred due to a particular limitation of the examiner, who was not able to exert the necessary force to adequately stabilize the segment when this muscle group exerted its maximum isometric strength. This type of limitation has been described in the literature for the evaluation of the strength of major muscular groups with portable dynamometry ${ }^{28,29}$. One disadvantage of the use of the non-adapted sphygmomanometer was the greater difficulty in stabilizing the equipment, most likely due to its larger contact area $\left(378 \mathrm{~cm}^{2}\right)$ in relation to the assessed segment and the examiner's hand, requiring more training for the evaluator to perform the test. When using such a method to evaluate strength, in addition to maintaining the flattened hand on the equipment, it is necessary that the examiner be able to stabilize the sphygmomanometer distally, avoiding even slight movements of the segments, as they might lead to slippage of the equipment and the need to repeat the measurement. This method required a greater need for training and more repetitions, because the loss of the necessary stabilization occurred more frequently.

The cuff adaptation is a simple, quick, and low cost method that uses readily available materials and can be easily used by professionals. Moreover, it is easily stabilized by the examiner, unlike the non-adapted sphygmomanometer. An important disadvantage of this method was that many individuals exceeded the readability of the equipment, limiting its use on stronger individuals.

The bag adaptation is the most commonly employed method in the literature ${ }^{8}$, and studies reported that it is able to provide more consistent 
measurements ${ }^{5,10}$, compared with the cuff adaptation. Among the three methods, this adaptation showed to be the easiest to be trained and stabilized. Although it requires the fabrication of a cotton bag (average cost of $\mathrm{R} \$ 15.00$ ), this bag facilitates the stabilization of the equipment and the containment of the inflatable part. However, this adaptation showed a lower ability to assess strength of stronger individuals compared to the other two MST methods.

Regarding the sources of outcome values, some studies investigated the best way to assess strength in healthy individuals with portable dynamometers ${ }^{30,31}$. Bohannon and Saunders ${ }^{31}$ investigated whether the values and test-retest reliability of three sources of measurements (first trial, highest value, and mean of three trials) to assess the strength of the elbow flexor muscles of healthy individuals were similar and reported no differences. Coldham et al..$^{30}$ investigated whether there was a difference in the test-retest reliability of the same sources of outcomes for the evaluation of handgrip strength of healthy individuals and individuals with various health conditions that affected their hands. They found that there were no differences and also reported that only one repetition was necessary. Furthermore, these authors also reported that a greater number of repetitions is more time-consuming ${ }^{31}$ and can lead to fatigue ${ }^{31}$ and pain $^{30}$. Taking into account the results of the present study and the disadvantages of obtaining a higher number of repetitions, only one repetition, after familiarization, could be performed for the assessment of strength in healthy individuals with the MST, regardless of the chosen method.

As previously mentioned, there were no systematic errors or inconsistencies of the measurements in successive calibrations, suggesting that the equipment can be used for repeated measurements of strength. Because the manufacturer recommends a full calibration of the sphygmomanometer every two years (depending upon the frequency of use) in an authorized service ${ }^{32}$, we suggest that this recommendation should be followed when the equipment is used to measure strength. The calibration performed in the present study does not need to be performed within clinical settings.

To ensure the internal validity of the present study, the reading and the recording of all strength measurements were conducted by an assistant examiner, whereas within clinical contexts, the same examiner is responsible for all stages of the evaluation. Future studies should investigate the consistency of the measurements when the same examiner is responsible for implementing the test and reading and recording the values.

The MST shows great potential for the clinical evaluation of strength because it is portable, inexpensive, and showed significant correlations with the portable dynamometer measures for all of the three investigated methods. The different characteristics should be considered when selecting the best method. Some characteristics favor the choice of a particular method. A detailed description of these characteristics was performed, so that the MST method can be selected to prioritize the characteristics that the examiner considers most important. For all the three investigated methods, the use of only one repetition, after familiarization, was shown to be adequate.

\section{Acknowledgments}

The authors thank the Minas Gerais State Research Foundation (Fundação de Amparo à Pesquisa do Estado de Minas Gerais - FAPEMIG), the Brazilian Federal Agency for the Support and Evaluation of Graduate Education (Conselho Nacional de Desenvolvimento Científico e Tecnológico - CAPES), the National Council for Scientific and Technological Development (Conselho Nacional de Desenvolvimento Científico e Tecnológico - CNPq) and the Dean's Office for Research Studies at the Federal University of Minas Gerais (Pró-reitoria de Pesquisa da Universidade Federal de Minas Gerais - PRPq/UFMG) for the financial support.

\section{References}

1. Conable KM, Rosner AL. A narrative review of manual muscle testing and implications for muscle testing research. J Chiropr Med. 2011;10(3):157-65. PMid:22014904 PMCid:PMC3259988.

2. Stark T, Walker B, Phillips J, Fejer R, Beck R. Hand-held Dynamometry correlation with the gold standard isokinetic dynamometry: a systematic review. Phys Med Rehabil. 2011;3(5):472-9.

3. Kelln BM, McKeon PO, Gontkof LM, Hertel J. Handheld dynamometry: reliability of lower extremity muscle testing in healthy, physically active, young adults. J Sport Rehabil. 2008;17(2):160-70. PMid:18515915. 
4. Hébert LJ, Maltais DB, Lepage C, Saulnier J, Crête M, Perron M. Isometric muscle strength in youth assessed by hand-held dynamometry: a feasibility, reliability, and validity study. Pediatr Phys Ther. 2011;23(3):289-99. PMid:21829128. http://dx.doi. org/10.1097/PEP.0b013e318227ccff

5. Helewa A, Goldsmith $\mathrm{CH}$, Smythe HA. The modified sphygmomanometer - an instrument to measure muscle strength: a validation study. J Chronic Dis. 1981;34(7):35361. http://dx.doi.org/10.1016/0021-9681(81)90073-4

6. Kaegi C, Thibault M, Giroux F, Bourbonnais D. The interrater reliability of force measurements using a modified sphygmomanometer in elderly. Phys Ther. 1998;78(10):1095-1103. PMid:9781703.

7. Lucareli PRG, Lima MO, Lima FPS, Gimenes RO, Lucareli JGA, Garbelotti Junior SA, et al. Comparison of methods of measurement of the finger flexor muscles' strength through dynamometry and modified manual sphygmomanometer. Einstein. 2010;8(2 -Pt 1):205-8.

8. Souza LAC, Martins JC, Teixeira-Salmela LF, Godoy M, Aguiar LT, Faria CDCM. Evaluation of muscular strength with the modified sphygmomanometer test: a review of the literature. Fisioter Mov. 2013;26(2):437-52. http://dx.doi. org/10.1590/S0103-51502013000200021

9. Bohannon RW, Lusardi MM. Modified sphygmomanometer versus strain gauge hand-held dynamometer. Arch Phys Med Rehabil. 1991;72(11):911-14. http://dx.doi. org/10.1016/0003-9993(91)90010-G

10. Helewa A, Goldsmith CH, Smythe HA. Patient, observer and instrument variation in the measurement of strength of shoulder abductor muscles in patients with rheumatoid arthritis using a modified sphygmomanometer. J Rheumatol. 1986;13(6):1044-9. PMid:3560090.

11. Helewa A, Goldsmith CH, Smythe HA. Measuring abdominal muscle weakness in patients with low back pain and matched controls: a comparison of 3 devices. J Rheumatol. 1993;20(9):1539-43. PMid:8164211.

12. Munro BH. Statistical methods for health care research. 5th ed. Philadelphia: Lippincott Williams \& Wilkins; 2005.

13. Faria CDCM, Teixeira-Salmela LF, Neto MG, Rodriguesde-Paula F. Performance-based tests in subjects with stroke: outcomes scores, reliability and measurement errors. Clin Rehabil. 2012;26(5):460-9. PMid:22008883. http://dx.doi.org/10.1177/0269215511423849

14. Centers for Disease Control and Prevention. Physical activity trends - United States, 1990-1998. MMWR Morb Mortal Wkly Rep. 2001;50(9):166-9. PMid:11393487.

15. Yancosek KE, Mullineaux D. Stability of handwriting performance following injury-induced hand-dominance transfer in adults: a pilot study. J Rehabil Res Dev. 2011;48(1):59-68. http://dx.doi.org/10.1682/ JRRD.2010.04.0074

16. Carregaro RL, Cunha RR, Cardoso JR, Pinto RS, Bottaro $M$. Effects of different methods of antagonist muscles preactivation on knee extensors neuromuscular responses.
Rev Bras Fisioter. 2011;15(6):452-9. PMid:22031273. http://dx.doi.org/10.1590/S1413-35552011005000028

17. Portney LG, Watkins MP. Foundations of clinical research: applications to practice. 3rd ed. New Jersey: PrenticeHall; 2009.

18. Kendall FP, McCreary EK, Provance PG. Muscles Testing and Function. 5th ed. Philadelphia: Lippincott Williams \& Wilkins; 2007.

19. Reis M, Arantes P. Assessment of hand grip strength - validity and reliability of the saehan dynamometer. Fisioter Pesqui. 2011;18(2):176-81. http:// dx.doi.org/10.1590/S1809-29502011000200013

20. Bohannon RW. Reference values for extremity muscle strength obtained by hand-held dynamometry from adults aged 20 to 79 years. Arch Phys Med Rehabil. 1997;78(1):2632. http://dx.doi.org/10.1016/S0003-9993(97)90005-8

21. Amaral JF, Mancini M, Novo-Júnior JM. Comparation of three hand dynamometers in relation to the accuracy and precision of the measurements. Rev Bras Fisioter. 2012;16(3):216-24. PMid:22801514. http://dx.doi. org/10.1590/S1413-35552012000300007

22. Martins JC, Souza LAC, Teixeira-Salmela LF, Aguiar LT, Lara EM, Faria CDCM. Assessment of muscle strength in stroke subjects with portable dynamometry: literature review. Fisioter Mov. In press, 2014.

23. Bohannon RW. Recovery and correlates of trunk muscle strength after stroke. Int J Rehabil Res. 1995;18(2):162-67. PMid:7665262. http://dx.doi. org/10.1097/00004356-199506000-00010

24. Bohannon RW. Test-retest reliability of hand-held dynamometry during a single session of strength assessment. Phys Ther. 1986;66(2):206-09. PMid:3945674.

25. Rice C, Cunningham D, Paterson D, Rechnitzer P. Strength in an elderly population. Arch Phys Med Rehabil. 1989;70(5):391-7. PMid:2719543.

26. Balogun J, Acomolafe C, Amusa L. Reproducibility and criterion-related validity of the modified sphygmomanometer for isometric testing of grip strength. Physiother Can. 1990;42(6):290-5.

27. Hamilton GF, McDonald C, Chenier TC. Measurement of grip strength: validity and reliability of the sphygmomanometer and Jamar grip dynamometer. J Orthop Sports Phys Ther. 1992;16(5):215-9. PMid:18796752. http://dx.doi.org/10.2519/jospt.1992.16.5.215

28. Martin HJ, Yule V, Dennison EM, Cooper C, Aihie Sayer A. Is hand-held dynamometry useful for the measurement of quadriceps strength in older people? A comparison with the gold standard Bodex dynamometry. Gerontology. 2006;52(3):154-9. PMid:16645295. http:// dx.doi.org/10.1159/000091824

29. Agre JC, Magness JL, Hull SD, Wright KC, Baxter TL, Patterson R, et al. Strength testing with a portable dynamometer: reliability for upper and lower extremities. Arch Phys Med Rehabil. 1987;68(7):454-8. PMid:3606371. 
30. Coldham F, Lewis J, Lee H. The Reliability of one vs. three grip trials in symptomatic and asymptomatic subjects. J Hand Ther. 2006;19(3):318-26. PMid:16861131. http:// dx.doi.org/10.1197/j.jht.2006.04.002

31. Bohannon RW, Saunders N. Hand-held dynamometry: a single trial may be adequate for measuring muscle strength in healthy individuals. Physiother Can. 1990;42(1):6-9.

32. Welch Allyn Ltd. DuraShock ${ }^{\mathrm{TM}}$ Integrated Aneroid Sphygmomanometer: directions for use. New York; 2008.

\section{Correspondence}

Christina Danielli Coelho de Morais Faria

Universidade Federal de Minas Gerais

Departamento de Fisioterapia

Av. Antônio Carlos, 6627, Campus Pampulha CEP 31270-901, Belo Horizonte, MG, Brasil

e-mail: cdcmf@ufmg.br; chrismoraisf@yahoo.com 